Review of Income and Wealth

Series 52, Number 4, December 2006

\title{
THE IT REVOLUTION ACROSS THE UNITED STATES
}

\author{
By Francesco DaVeri* \\ University of Parma and IGIER \\ AND \\ Andrea Mascotto \\ Stockholm University
}

In this paper we study the geography of the IT revolution in the U.S. economy. By relating the intensity of IT production and diffusion to labor productivity growth for the United States, we find three main results. First, states with above-average production intensity of IT manufacturing show more growth acceleration than other states. Second, the same applies to states with above-average IT diffusion. Yet, while the result for IT-producing states is strong, the result for IT-using states is somewhat smaller and less robust across specifications. Third, we also reconcile our state-wide pieces of evidence with previous industry and aggregate evidence. Accelerating productivity growth in IT-producing states stems from both IT-producing and IT-using industries in those states and is not a manifestation of the exclusive importance of IT production. Moreover, the less robust evidence for IT-using states is due to lower growth contributions from IT-producing and other industries in these states, not a symptom of a missing effect of IT usage.

\section{INTRODUCTION}

Information technology (IT) is the recognized engine of the post-1995 U.S. productivity revival. This result has been documented with aggregate, industry and company data in the last five years or so.

Aggregate and industry level studies (Jorgenson and Stiroh, 2000; Oliner and Sichel, 2000; Nordhaus, 2002; Stiroh, 2002a, 2002b; Triplett and Bosworth, 2003), quantified the contributions of IT production and usage to labor productivity growth in the U.S. economy in an additional full percentage point per year or so since the 1990s. The importance of IT usage - and its related organizational changes - for productivity growth has also been confirmed by a host of other

Note: This paper is part of the research project "La New Economy nel mondo" ("The New Economy in the world") funded by the University of Parma. We are very grateful to two referees and the editor, Bart van Ark, for their comments, which greatly helped us shape our argument. We are also indebted to Barbara Fraumeni, Robert Gordon and Hugh Knox for their advice at an early stage of this project, as well as to Olmo Silva, Jack Triplett and other seminar participants in the ICT Conference in Mannheim and at the University of Brescia, Bocconi and LUISS (Rome) for their comments on previous drafts.

*Correspondence to: Francesco Daveri, Professor of Economics, Università di ParmaDipartimento di Economia, Sezione di Scienze Economiche, Via Kennedy 6, 43100 Parma, Italy (francesco.daveri@unipr.it).

(C) 2006 The Authors

Journal compilation (C) 2006 International Association for Research in Income and Wealth Published by Blackwell Publishing, 9600 Garsington Road, Oxford OX4 2DQ, UK and 350 Main St, Malden, MA, 02148, USA. 
studies using company data. Notably, Brynjolfsson and Hitt (2003) found very large productivity-enhancing effects of IT usage. ${ }^{1}$

In other studies, the importance of IT diffusion as an engine of permanent productivity growth has been questioned. In his early contributions on this topic, Gordon $(2000,2003)$ forcefully stressed that the U.S. productivity acceleration of the 1990s, netted out of business cycle influences and other one-shot shocks affecting positively IT investment demand (such as the birth of the World Wide Web in the early 1990s and the Millennium Bug fears in 1999), was narrowly concentrated in a few IT-producing industries (notably the computer industry). Yet most of the doubts on the importance of IT for growth have gradually disappeared due to the resilience of the productivity boom of the U.S. economy. The productivity revival continued and possibly accelerated in the 2000s, irrespective of a sequence of negative shocks such as the dotcom bust, terrorist attacks and various corporate scandals. ${ }^{2}$ Altogether, while hardly anybody would deny either the propelling role of computers and semiconductors or the contribution of IT using industries in making productivity gains permanent throughout, opinions may still differ as to the relative importance of IT production and usage for the observed behavior of U.S. productivity. ${ }^{3}$

This paper contributes to the literature on the effects of the IT revolution in the U.S. economy exploiting the largely unexplored geographical dimension of the IT revolution. We begin by presenting the basic geography of the IT revolution, i.e. the facts about IT diffusion and labor productivity growth across the United States. This is done rather extensively because such data have not received much attention in the past, with the recent exception of Daly and Furlong (2005). ${ }^{4}$ Moreover, the mere undertaking of measuring the intensity of IT diffusion and labor productivity growth at the state level is not a trivial task and raises novel methodological issues, which deserve some discussion. The Bureau of Economic

\footnotetext{
${ }^{1}$ See also van Ark (2002) for a discussion. The relatively low social rate of return on ICT investment may be the result of measurement error. It may also indicate significant creative destruction effects. For a few industries, however, industry rates of return may actually be higher than those recorded in companies' balance sheets. McGuckin et al. (2005) argue that the role of technological and managerial "champions" is not exhausted by their direct contribution to industry and aggregate productivity. Champions may also indirectly make the industry (and, possibly, the economy) more efficient through their market relations with customers and suppliers as well as with their unceasing pressure to enhance labor quality and management practices.

${ }^{2}$ Two influential reports from the McKinsey Global Institute are notable examples of the emergence of a balanced view of the benefits brought about by the IT revolution. MGI (2001) emphasized that the productivity revival of the late 1990s has been entirely driven by six industries, while MGI (2005) concluded that, after the dotcom bust, productivity growth has become a less narrow phenomenon, with the top seven industries contributing only about 85 percent of the total growth of labor productivity.

${ }^{3}$ This debate has been echoed outside the U.S. as well. The assertion that IT usage is behind the (lack of) productivity acceleration in Europe has been made by van Ark et al. (2003a, 2003b), where the EU-U.S. growth gap has been shown to originate in three large IT-using industries only (wholesale trade, retail trade, financial intermediation). Gordon (2004) asserted that differences in land and other (non-IT-related) regulations, rather than IT-usage as such, may have eventually caused such discrepancies. Daveri (2004) showed how the relative importance of differences in IT usage vs. other factors in fact depends on which industries are included in the category of the IT-using industries, retail trade being the most obvious object of contention. These issues are further discussed in the main text.

${ }^{4}$ Daly and Furlong graphically contrast the productivity gains in the U.S. states in 2001-04 with those in 1997-2000 and draw inference on the permanent nature of such gains through graphical tools. They do not undertake any econometric analysis, though.
} 
Analysis (BEA) of the U.S. Department of Commerce provides evidence on the extent of the productivity revival at the state level. The revival was indeed widespread: in 1995-2000, 40 states in the U.S. recorded higher growth rates of labor productivity in the business sector than in previous years. To evaluate whether such trends are related to the IT revolution, we used BEA and Census data. For this purpose we constructed various indicators of the geographical intensity of IT production and usage across the U.S. Our measures indeed show a significant, but clearly not uniform, diffusion of IT across the U.S.

In the second part of this paper, we relate the heterogeneity in IT production and diffusion at state level to their productivity performance. This is done by running difference-in-difference regressions of labor productivity growth. The regressor list includes period controls, state controls (grouped by their intensity of IT diffusion) and state-period interaction terms. The use of such controls allows one to evaluate whether the post-1995 productivity acceleration has been more marked in IT-intensive states after 1995. In other words, our statistical analysis is a way to estimate the causal effect of IT diffusion and production (the "treatment") on the post-1995 acceleration in the growth rate of labor productivity. This basic methodology - essentially the same as in Stiroh (2002b) - allows us to exploit both the time series and the cross-state variation in the productivity data to test for the presence of group-specific deterministic breaks in productivity growth.

Our statistical results are largely in accordance with the prevailing views on the crucial importance of IT production and use in the U.S. productivity revival. The analysis of the state dimension adds three important insights as to how productivity gains spread throughout the U.S. economy. First, states with aboveaverage production intensity of IT manufacturing (essentially computers, telecoms equipment and semiconductors, as classified under the 1997 NAICS code 334) showed a faster post-1995 acceleration in productivity growth (for about 1.2-1.5 percentage points) than other states. Second, states with above-average diffusion of computers at work - our preferred measure of IT diffusion and use - also show more productivity acceleration higher than other states. Yet, while the evidence on a positive productivity impact from IT production is quite strong and survives various changes of specification in the estimating equation, the result for IT usage is somewhat less robust. It survives some changes of specification but not all of them. This is seemingly at odds with the industry evidence discussed above, which instead points to a significant link between IT use and accelerating labor productivity growth. Our third result is a proposed solution for this puzzle. By disaggregating Gross State Product (GSP) across industries and looking at the industry group performances in each group of states, one finds that the above-average productivity acceleration of IT-producing states is the counterpart of very high growth contributions of both IT-producing and IT-using industries in those states. It is thus not a manifestation of the exclusive importance of either IT-producing or IT-using industries. Likewise, the less pronounced productivity acceleration in IT using states is mostly the result of lower acceleration and somewhat lower value added shares of IT-producing industries as well as negative growth contributions from non-IT-related industries in those states. It is thus not a symptom of a missing effect of IT usage on productivity growth. This reconciles our state-level evidence with the evidence from previous aggregate, industry and company studies 
which pointed to the importance of both IT production and IT diffusion in triggering the productivity revival.

The structure of this paper is as follows. In Section 2, data and measurement issues are discussed. Section 3 takes a first look at the data on the diffusion of IT and the behavior of labor productivity growth across the U.S. In Section 4, the statistical relation between IT production and use and the post-1995 productivity revival is analyzed at the state level. Section 5 reconciles our state evidence with previous evidence by presenting the results of a disaggregation of state productivity growth for IT-producing, IT-using and other states by industry group. Section 6 concludes.

\section{Data Sources and Measurement Issues}

Our work requires information on two sets of state-level variables: IT diffusion and production, on the one hand, and the growth rate of labor productivity, on the other. In this section, we describe data sources and measurement issues. More details on data and measurement issues are provided in the Data Appendix.

\section{Data Sources}

\section{Information Technology}

Direct information about IT penetration is from the Current Population Survey (CPS) Supplements, released by the Census Bureau at the U.S. Department of Commerce. Information on computer and internet use at home and at work are available for specific reference years and for many localities, including all of the 50 states and the District of Columbia (from here onwards, we sometimes refer to "51 states" for brevity). Data on computer use at home are for 1994, 1997, 1998, 2000, 2001 and 2003; data on computer use at work are only available for 1997, 2001 and 2003. Note, however, that the most recent data are unfit for our purposes, as we are meant to evaluate whether state-wide IT intensity before the productivity acceleration is a good predictor of the revival during the second half of the 1990s. Hence, as discussed below, we classify industries and states using indicators measured around 1995, i.e. 1997 for PC use at work (our preferred measure of IT use) and 1994 for household computer diffusion. For robustness check purposes, we also employ indirect measures of IT diffusion, based on industry data at the SIC level of classification for 1991-95. The IT diffusion in a given state may in fact be indirectly inferred by combining nationwide information on the IT intensity of each industry and data on the industry structure of each state (see below). This latter piece of information comes from the BEA website.

\section{Labor Productivity}

Computing labor productivity requires state-level data on real output and a measure of the labor input. The available output measure from the BEA is the Gross State Product by industry (GSP), the sum of the value added originating in all industries in each state. The available industry breakdown is at the two-digit 
SIC level for all the states and the District of Columbia. ${ }^{5}$ The BEA provides estimates of GSP for the non-farm business sector (thus excluding agriculture, government and government enterprises) at current dollars. A measure of GSP at constant prices is also available but it is based on national industry deflators. The data employed here span from 1977 to 2000 for GSP in current dollars and quantity indexes, and from 1986 to 2000 for chained-dollar GSP. Given that the chained dollar estimates are free of upper-level substitution bias, the baseline results of this paper are obtained from the shorter 1986-2000 data set. Estimates obtained from the longer 1977-2000 data set are also shown, however.

The productive input of labor is measured in terms of total employment, being the number of average hours worked not available at the state level. Total employment by place of work refers to full and part-time employment of wage and salary earners as well as self-employed persons. This variable is also obtained from the BEA website.

\section{Measurement Issues}

To evaluate whether there is a relation between IT diffusion and productivity growth at the state level, a few measurement issues need to be addressed. First, one has to choose a synthetic index to identify state groups according to preset criteria. Below we describe such an index. Then, we describe the criteria to identify states specialized in the production of IT manufacturing and states specialized in the production of IT-using goods and services. Finally, the issues involved in the computation of state labor productivity are discussed.

\section{A Synthetic Index of Geographical Specialization}

We look for a summary statistics conveying two pieces of information. First, we require the index to embody information on the IT intensity (production or use) for a given state. Second, we need a synthetic index that tells us whether the values taken by the state-specific indicators are higher or lower than a nationwide counterpart, which we take to be the country average. A synthetic index with these features is the following:

$$
S I_{i}^{s}=\frac{y_{i}^{s} / y^{s}}{y_{i} / y}=\frac{y_{i}^{s} / \sum_{i} y_{i}^{s}}{\sum_{s} y_{i}^{s} / \sum_{i} \sum_{s} y_{i}^{s}}
$$

where $y_{i}^{s} / y^{s}$ denotes a variable such as the production of IT goods manufacturing as a share of total production, the share of workers using a PC at work, or the share of families using a PC at home. Each of these variables measures a characteristic $i$ associated with IT intensity in state $s$. For the denominator of the index in (1), this same characteristic is measured for the U.S. as a whole.

In our statistical analysis in the next sections, we use (1) to construct both continuous and discrete indices. The values of the $S I_{i}^{s}$ are continuous indicators of

${ }^{5}$ Additional information on data construction and sources can be found in Beemiller and Woodruff (2000) and Friedenberg and Beemiller (1997). 
IT intensity centered on one, and varying between zero and infinity. We also use a discrete version of $S I_{i}^{s}$, that is a step-wise indicator taking the value of one in case $S I_{i}^{s}$ is equal to or greater than one, and zero otherwise. It thus equals one if the value of the characteristic $i$ in state $s$ is bigger than or equal to the value taken by the same characteristic for the U.S. as a whole. As the index takes values above or equal to one, this signals that state $s$ is specialized in characteristic $i$. A state may then be labeled an "IT-producing state" (respectively, an "IT-using state") if the value of $\mathrm{SI}_{\text {ITprod }}$ ( (respectively, $\mathrm{SI}_{\text {ITuse }}$ ) is bigger than or equal to one.

As can be seen from the statistical analysis below, the estimates obtained from the discrete indicator are amenable of immediate interpretation in terms of trend breaks. The shortcoming of this indicator is that, as shown in Table 1, its values fall between 0.95 and 1.05 for many states. Hence, the information provided by the discrete indicator may be rather inaccurate at times. States with $S I_{i}^{s}=0.99$ would be classified as non-specialized in characteristic $i$, while states exhibiting $S I_{i}^{s}=1.00$ would be specialized in that characteristic. Given that such discontinuities are probably unreasonable and - what is worse - a possible source of bias, we check to what extent our results depend on drawing such point-wise boundaries.

Finally, in principle, SI can be computed for any of the years for which BEA data are available throughout our period of analysis (1986-2000 or 1977-2000, depending on the specific output variable). But we want to employ a measure of IT intensity around 1995 to infer whether the chosen index can predict the acceleration of productivity growth in the second half of the 1990s.

\section{Identifying IT-Producing States}

Identifying which states produce IT manufacturing goods is relatively straightforward. The U.S. Census Bureau has recently singled out, given its economic significance, the "Computer and Electronic Product Manufacturing" industry (NAICS 334) within the overall manufacturing sector. This sub-sector includes establishments that manufacture computers, computer peripherals, communications equipment and similar electronic products, as well as establishments that manufacture components for such products (mainly, but not only, semiconductors). The size of the sector may be measured in terms of employment or production. Our computations below are based on production data. Data for this sub-industry group are available from 1997 onwards. It would be desirable to classify states accordingly to the value taken by a variable measured before 1995 , i.e. the start of the productivity revival. We took data for the earliest possible year (1997) and classified the states according to the values taken by $\mathrm{SI}_{\text {ITprod }}$ for that year.

As an alternative, one could also use a list of IT-producing states which was provided by the Economics and Statistics Administration of the U.S. Department of Commerce for the period 1991-95 (ESA-DC; U.S. Department of Commerce, 2002). Here an IT-producing industry is defined as one which "supports IT-enabled business practices and processes across the economy, as well as the Internet and e-commerce." An important problem with this definition is that it cannot be

\footnotetext{
${ }^{6}$ The Department of Commerce definition has been employed by Beemiller and Downey (2001) and Nordhaus (2002).
} 
directly measured at the state level, but has to be proxied at the two-digit SIC industry level for which GSP estimates are available. At the two-digit level, the list of "IT-producing states" would include all states with above-average production in: (i) industrial machinery and equipment (inclusive of computer and related hardware manufacturing); (ii) electronic and other electrical equipment (inclusive of semiconductors manufacturing and related products); (iii) telecommunications (TLC, inclusive of phone, satellite and multimedia services); and (iv) business services (inclusive of software development, data processing services and computer rental and leasing). This is a very imprecise classification. For example, in 1995, the computer industry made up only about one quarter of "industrial machinery," while the semiconductors and TLC equipment share was only 60 percent of "electronic and electric equipment." On the services side, the TLC industry also included radio and TV broadcasting for about one quarter of the total, while software services only made up 35 percent of business services. Hence, in practice, the ESA-DC classification is too coarse to precisely identify "production of IT goods and services."

We chose the share of IT manufacturing output in total output in 1997 as a classification criterion, hoping to capture the phenomenon we are after, i.e. whether being endowed with a high share of IT manufacturing makes a difference for productivity trends, more precisely at the risk of reverse causation. ${ }^{7}$ A final difficulty in this respect is that, for six states (Alaska, DC, Hawaii, Montana, Vermont and Wyoming), the data necessary to compute our preferred indicator are unavailable or not disclosed for confidentiality reasons. The value of the index for these states has thus been replaced by the share of "industrial machinery" and "electrical and electronic equipment" over total output. To check that this does not bias our results, estimates are reported for the full sample and for the restricted sample that excludes these six states.

\section{Identifying IT-Using States}

The diffusion of IT in the U.S. economy can be directly measured by looking at the data on PC diffusion obtained from the Current Population Survey (CPS) Supplements. For the purpose of this paper we would like to observe a characteristic related to the extent of IT adoption for the companies localized in any given state. A proxy for computer diffusion and use at work is the ratio between the number of respondents answering yes to the question "Does anyone in this household directly use a computer at work?" and total state employment. These data are available from 1997 onwards.

Here as above, we are meant to explore the link between the extent of IT diffusion in the mid 1990s and accelerating productivity growth thereafter. By using an IT intensity classification relative to 1999 or 2000 , we may not capture the association between IT intensity and labor productivity, but possibly the effect of rapid productivity increases - caused by, say, favorable cyclical

${ }^{7}$ In evaluating the likelihood of reverse causation, it should be considered that output shares change very slowly over time and by fairly minor amounts. Moreover, the risk of reverse causation is not really eliminated even with data from the early 1990s, because it may well be the case that IT investment surged just in those industries where rapid productivity increases had been anticipated. 


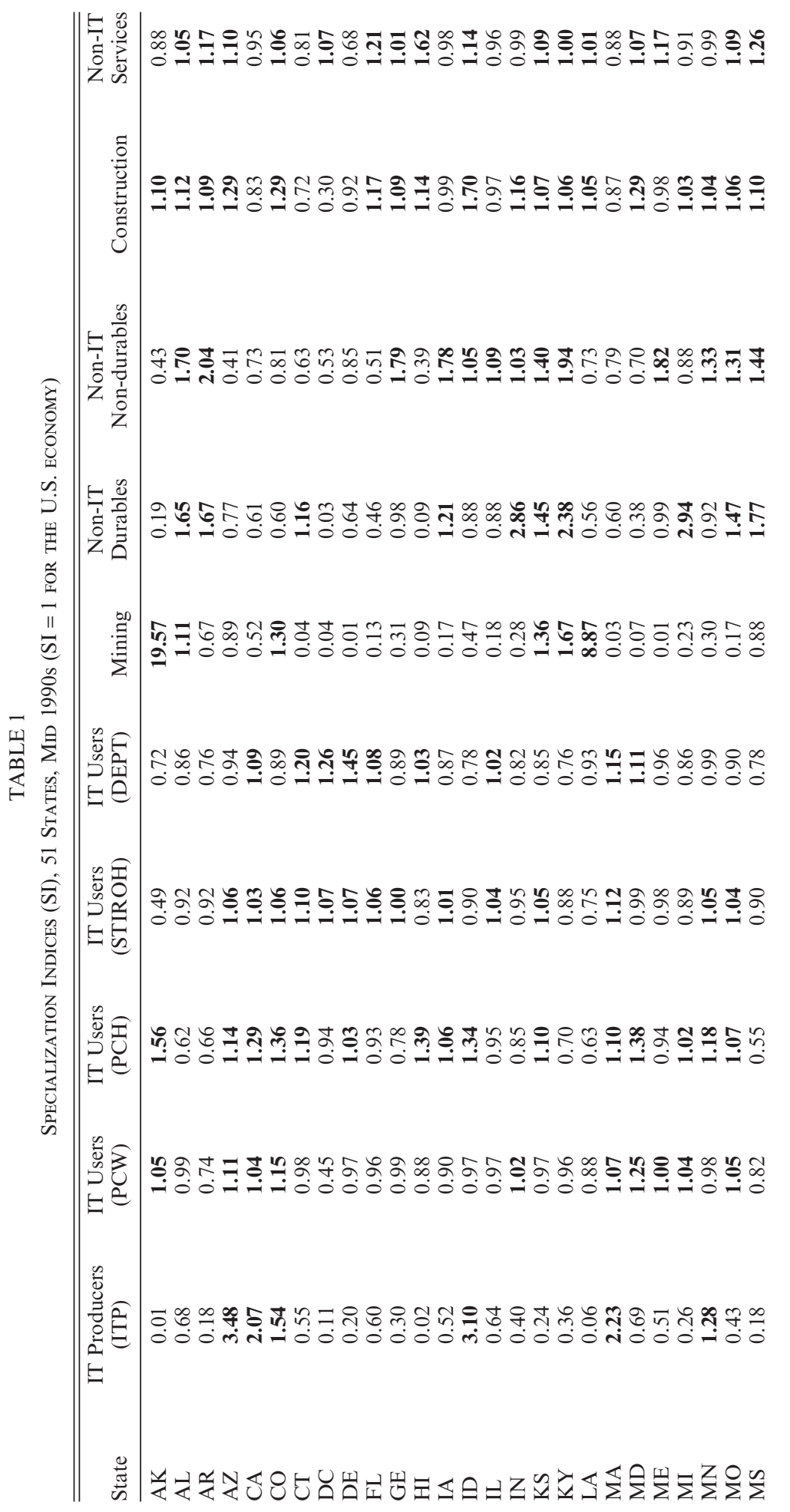




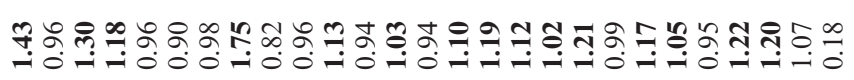

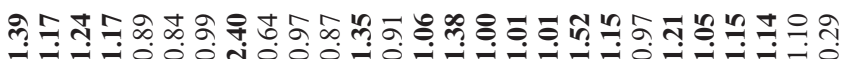

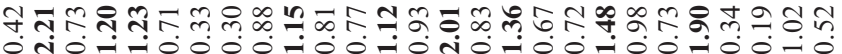

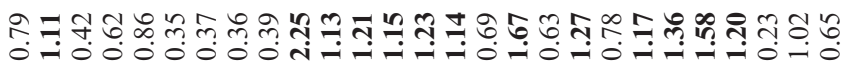

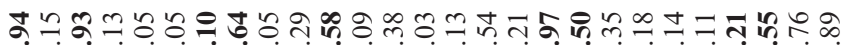

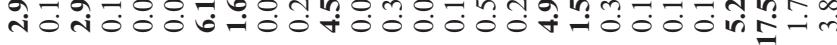

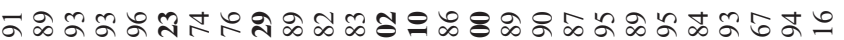

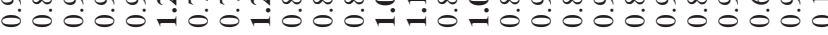

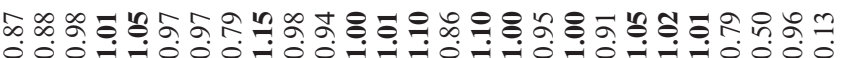

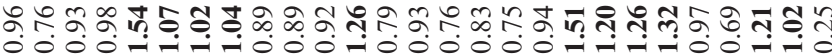
б̆ڤ

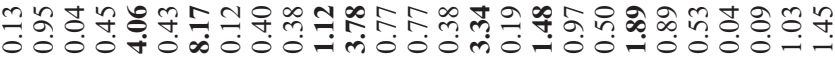

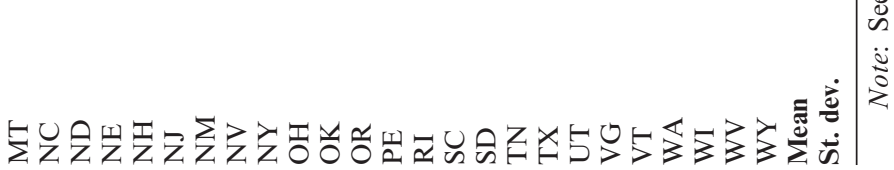


circumstances - on the adoption of information technologies. With this caveat in mind, among the available data, we employ those closest to the breakpoint for productivity growth (1995). This is why our data on computer use at work refer to 1997.8

Data on household ownership of a PC are available for the period prior to 1995. Yet owning a PC does not necessarily imply that it is used. Moreover, using a PC at home does not always entail a "productive" use of a PC, given the use during leisure time of workers and non-workers like children or the elderly. Household ownership of PCs is thus a rather imprecise indicator of what we are aiming to measure. In any case, we constructed an indicator from this variable as well, as the ratio between the number of respondents answering yes to the question "Does anybody in this household own a personal computer?" and the total number of households in each state in the earliest available year, $1994 .^{9}$ In our econometric work, we construct the specialization index SI described above for both indicators of PC diffusion. The specification of PC use at work (PCW) will be our baseline specification. The results obtained with the PC household ownership (PCH) indicator will be shown in the robustness checks table.

Finally, the information on IT usage derived from our PCW variable can be contrasted with a third indirect measure of IT usage by state, using investment data. This requires one to gather information on the IT intensity of industries at the U.S. national level and then draw inference on IT usage in a given state from the industry mix of that state. If the output share of IT-using industries in a given state is above its national average, then that state may be labeled an "IT-using" state. This is likely an imprecise measure of IT intensity for two possible reasons. First, there is some disagreement on how to identify IT-using industries using investment data at the national level. Stiroh (2002b) labeled "IT users" as those industries whose IT shares of total capital services were ranked above the median of the industry distribution in 1995. The U.S. Department of Commerce, instead, has used a more restrictive definition, labeling "IT-users" as those industries in the top 25 percent of the list of the non-farm business industries with the highest installed IT capital stock and investment flows. As a result, two very different lists of "IT-using industries" - and, related to that, "IT-using states" - may be drawn. The biggest difference between the Stiroh and the Department of Commerce classifications (labeled STIROH and DEPT below) concerns the treatment of retail trade. The STIROH list includes retail among the IT-using industries, while the DEPT list does not. The inclusion of retail among the IT-intensive industries

\footnotetext{
${ }^{8}$ Although we cannot be sure that the state ranking in 1995 would have been the same as in 1997 , we can show that the correlation coefficient between 1997 and 2001 data is very high (0.82), with a similarly high ranking correlation coefficient.

${ }^{9}$ Using data for 1994 or 1997 does not make a big difference. The correlation coefficient between 1997 and 1994 data is very high (0.88) with a ranking correlation coefficient of 0.83 . The states lowering the correlation coefficient below one are Hawaii and Wyoming. In these states, PC ownership was above the national average in 1994, while the increase between 1994 and 1997 has seemingly been much smaller than the average increase experienced in the U.S. Both states belong to the group of states whose influence on the econometric results is tested in the robustness check section (see the estimates from the restricted sample).
} 
sounds particularly problematic if one considers that IT intensity in retail is below the mean in the distribution of the U.S. industries. ${ }^{10}$

A second concern about using investment-related data is that, even after having settled for one specific criterion to distinguish IT-using industries from non-IT industries, one needs to assume that - say - the business services industry is as IT intensive in Louisiana as in California. If this assumption does not hold, the actual extent of IT use would be imprecisely captured by the industry-based indirect indicator of IT use and likely bias the estimates of the relation between IT usage and productivity towards zero.

In conclusion, given the variety of measurement issues which plague indirect industry-based measures of IT usage, we decided to employ PCW - a direct indicator - as our preferred measure of IT usage at the state level. Yet we check the robustness of our baseline results by presenting results for other specifications where PCW is replaced by PCH, STIROH or DEPT.

\section{Measuring Labor Productivity}

Our indicator of labor productivity is imperfect for reasons that are more or less well known. Starting with the well known ones, GSP is a value added and not an output measure. It is produced from the income side of the accounts as the sum of employees' compensation, indirect taxes and property-type income. Secondly, business cycle influences are not filtered out from our productivity indicator. Estimating cyclical adjustment for each individual state would, however, introduce considerable noise into the analysis, given that industry GSP data are deflated by national price indices. Even a fully fledged attempt to net out businesscycle influences with our information set would not resolve the problem of distinguishing between residual price-change elements and pure quantity-change components.

Other, less well-known, measurement problems come about when analyzing state data. Firstly, GSP is the state counterpart of the nation's GDP. While income and output are almost the same at the nation level, this is unlikely to be the case for states in particular when there are many differences between legal ownership and the localization of production is significant. Suppose that the production of certain goods is located in Ohio while its income accrues to a holding located in the state of New York. There may be two reasons for why the proceeds of such a production process would be imputed to New York. First, there may be a difference between the place of residence and the place of work for proprietors' income. Second, it might also be controversial how to allocate the "corporate profits" items within the bigger "other capital charges" item across states. These problems are discussed at greater length in the Data Appendix (see the section on "Measuring output at the state level").

\footnotetext{
${ }^{10}$ Based on 1979-95 data (hence, data prior to the productivity revival) reported by Inklaar et al. (2003), the retail industry ranks 9th among the IT-intensive users. This is well within the 50 percent median threshold chosen by Stiroh. Yet, during that period of time, retail trade was actually generating less IT capital services than the average industry in the whole U.S. economy ( 2.8 against 3.4 percentage points of value added).
} 


\section{Conclusions on Measurement Issues}

In conclusion, our data suffer from several potential sources of bias. In many cases, the bias is probably small. It should also be kept in mind that the bulk of our analysis concerns the growth rates of labor productivity or their period changes from the first to the second half of the 1990s, while biases in most cases should affect levels. Any state-specific bias would thus likely wash out as long as these are time-invariant. We are therefore inclined to conclude that the first-order effect of these biases is probably very small as well. In the following sections, our baseline results are based on one indicator of labor productivity (real GSP over total employment), one indicator of IT production (the share of IT manufacturing production over total GSP) and one indicator of IT usage (the employment share of households with at least a member using a PC at work). In the extensions, sensitivity analysis results are also presented to check whether the baseline results survive a few changes of specifications.

\section{A First Look at the Data}

\section{IT Production and Diffusion}

Following the methodological criteria described in Section 2, states have been classified according to the values of their specialization indices. Table 1 reports the values of SI for IT production and IT usage (PCW, PCH, STIROH, DEPT) that we have compiled for all states. Figures 1 and 2 depict the geographical mapping of the values of the IT production and usage (PCW) indices respectively. Thirteen states (about 32 percent of total output and 31 percent of total employment in the United States in 1997) are specialized in the production of IT manufacturing goods. The industry shares of IT manufacturers located within their territory are above the national average of 3.5 percent. The state list includes (in descending order of their $\mathrm{SI}_{\text {ITprod }}$ index), New Mexico, New Hampshire, Oregon, Arizona, South Dakota, Idaho, Massachusetts, California, Vermont, Colorado, Texas, Minnesota and Oklahoma. New Mexico presents a value of the $\mathrm{SI}_{\text {ITprod }}$ above 8, while $\mathrm{SI}_{\text {ITprod }}$ for Oklahoma is just above the country average (1.1). Massachusetts and California present values of $\mathrm{SI}_{\text {ITprod }}$ slightly in excess of two. Nine of the 12 IT-producing states also belong to the group of intensive IT-using states, according to the values of PCW-our preferred measure of IT usage. But the list of IT-using states according to the values of PCW is much longer and includes 22 states, which represent about 57 percent of total output and 56 percent of total employment. In such states, the share of households with a member using a PC at work was above or equal to 41 percent - the average for the U.S. economy. The states most intensively using IT in 1997 are Maryland, New Hampshire, Washington and Arizona, where the values of the $\mathrm{SI}_{\text {ITuse-pcw }}$ range between 1.11 and 1.25. At the other extreme, the states least intensively using IT in 1997 are DC (with a bare 0.45), Arkansas, Nevada and Mississippi (with values for the $\mathrm{SI}_{\text {ITuse-pww }}$ close to $0.8)$.

The data on IT production and IT usage in Table 1 confirm a rather well known fact: the production of IT manufacturing goods was (and still is today) more geographically concentrated than IT diffusion. This is clearly reflected in 


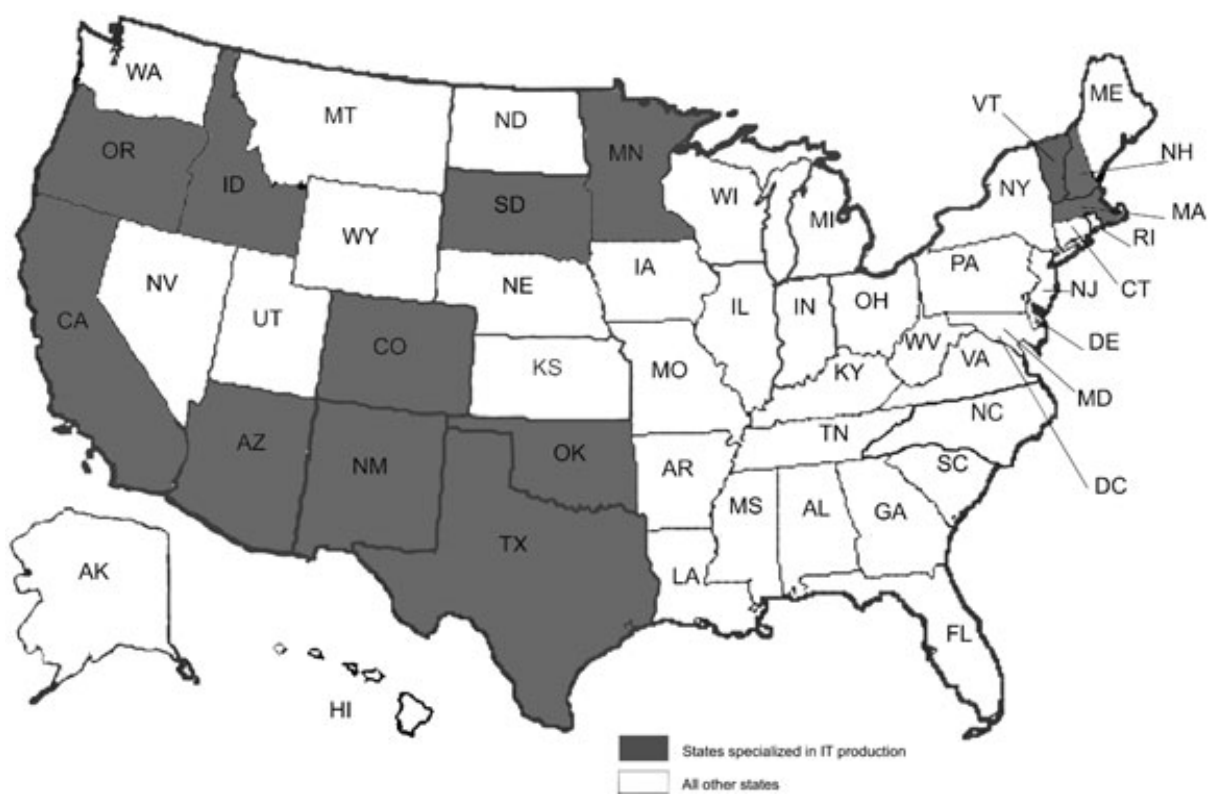

Figure 1. IT Production

the much higher standard deviation of the SI index for IT production (1.45) than for the IT usage indicators $(0.13-0.25) .{ }^{11}$ A related, somewhat problematic, aspect of the lower variability of the IT usage classification is that for many states the SI indices take values very close to one. For PCW, 13 states present values for the SI within the 0.97-1.03 interval. Things are even worse for STIROH (16 states), while the problem is less serious for PCH and DEPT (with six states each). To learn about the extent of the potential bias from "excess categorization," we run regressions using both discrete and continuous versions of the SI indicators.

Table 2 describes the pattern of pair-wise correlation between IT production and IT usage. Two main observations emerge. First, the correlation coefficient between the SI for IT production and IT use is usually rather low, though higher for PCW (0.35) than for the other indicators of IT usage (PCH, STIROH and DEPT, which exhibit correlation coefficients of respectively $0.27,0.26$ and -0.03 ). Second, classification criteria seem to matter a lot. The correlation between PCW and PCH is about 0.5 . But the correlation between PCW and STIROH or DEPT is instead very low, respectively 0.15 and -0.01 . This confirms that the different indicators of IT usage are not very close substitutes for each other.

Finally, for convenience, Tables 1 and 2 also report information on the degree of specialization of the various states in the other industry groups. Not surprisingly most, if not all, states are not specialized in one single industry group, but often show

${ }^{11}$ In turn, this difference stems from within-region rather than cross-region variability. Since there is at least an IT producer in each region, differences across states are more pronounced within the eight broad BEA regions (New England, Mid East, Great Lakes, Plains, South East, South West, Rocky Mountain and Far West) than across regions. 


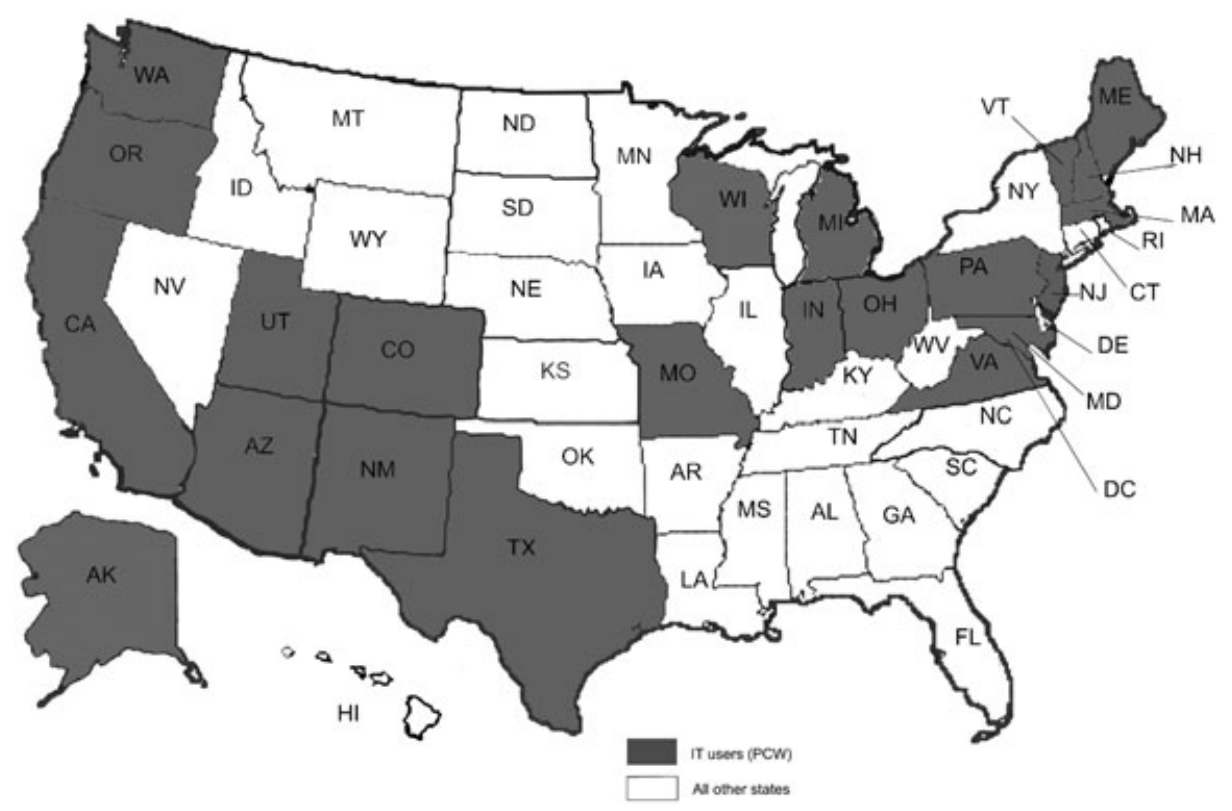

Figure 2. Computer Use at Work (PCW)

an above-average presence in a variety of industries. It might thus be the case that the productivity performance of those states that we label "IT-intensive" is in fact driven by their specialization in some other sectors, whose presence only happens to be highly correlated with IT intensity. But the pattern of pair-wise correlations between the SI indices in Table 2 shows that this is unlikely to be the case. Correlation is often low (and not statistically different from zero), in particular for the SI indices of IT production and use. We regard this as an indication that the risk of spurious correlation between IT intensity and productivity growth is low.

\section{Labor Productivity}

Table 3 presents data for labor productivity growth data over the period 1986-2000, with a split in 1995. The years before 1995 represent the final part of the productivity slowdown period. The maximum growth rates of labor productivity during the pre-1995 period were near 2 percent. Three states, New Hampshire (2.3 percent), New Jersey (2.3 percent) and Connecticut (2.25 percent), were the fastest growers, with another five states (New Mexico, Massachusetts, Rhode Island, Delaware, and South Carolina) clustering around 1.8 percent per year. In parallel, ten states showed negative or zero yearly productivity growth throughout the whole period. In other words, the pace of growth was disappointing in the United States in general, and the fastest productivity growth at some 2 percent per year was by and large restricted to New England states.

Things dramatically changed during the second half of the 1990s. Whereas productivity growth did not reach 2.5 percent per year in any of the states in 1986-95, 16 states experienced productivity growth rates beyond 2.5 percent per 


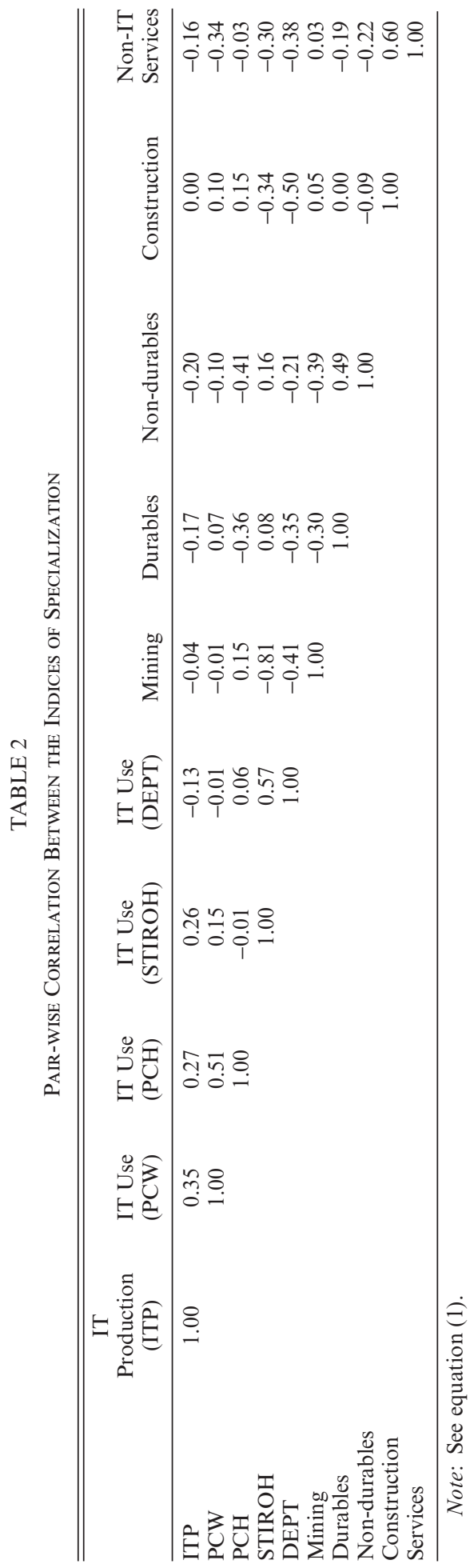


TABLE 3

Labor Productivity Growth in the U.S., 1986-2000

\begin{tabular}{|c|c|c|c|c|}
\hline State & Region & $1995-2000$ & $1986-95$ & $(1995-2000)$ to $(1986-95)$ \\
\hline OR & Far west & 5.57 & 1.09 & +4.48 \\
\hline $\mathrm{MN}$ & Plains & 3.40 & 0.44 & +2.96 \\
\hline UT & Rocky Mountains & 2.54 & -0.03 & +2.58 \\
\hline WA & Far west & 3.30 & 0.74 & +2.56 \\
\hline $\mathrm{CA}$ & Far west & 3.44 & 0.91 & +2.53 \\
\hline ND & Plains & 2.11 & -0.26 & +2.37 \\
\hline $\mathrm{NH}$ & New England & 4.55 & 2.30 & +2.25 \\
\hline $\mathrm{CO}$ & Rocky Mountains & 3.34 & 1.13 & +2.22 \\
\hline MA & New England & 4.01 & 1.83 & +2.19 \\
\hline RI & New England & 3.76 & 1.86 & +1.90 \\
\hline $\mathrm{NC}$ & Southeast & 2.98 & 1.09 & +1.89 \\
\hline $\mathrm{KS}$ & Plains & 2.05 & 0.16 & +1.89 \\
\hline NY & Mid East & 3.30 & 1.42 & +1.88 \\
\hline MI & Great Lakes & 1.86 & 0.06 & +1.80 \\
\hline $\mathrm{AZ}$ & Southwest & 3.10 & 1.37 & +1.73 \\
\hline ID & Rocky Mountains & 3.09 & 1.50 & +1.59 \\
\hline MT & Rocky Mountains & 0.79 & -0.76 & +1.55 \\
\hline $\mathrm{NE}$ & Rocky Mountains & 0.79 & -0.76 & +1.55 \\
\hline WI & Great Lakes & 2.33 & 0.80 & +1.53 \\
\hline IN & Great Lakes & 2.45 & 0.93 & +1.52 \\
\hline NM & Southwest & 3.29 & 1.93 & +1.36 \\
\hline USA & & 2.31 & 0.95 & +1.36 \\
\hline GE & Southeast & 2.73 & 1.40 & +1.33 \\
\hline $\mathrm{OH}$ & Great Lakes & 1.76 & 0.57 & +1.20 \\
\hline IL & Great Lakes & 2.27 & 1.13 & +1.14 \\
\hline SD & Plains & 1.21 & 0.16 & +1.05 \\
\hline TX & Southwest & 2.06 & 1.22 & +0.84 \\
\hline $\mathrm{OK}$ & Southwest & 0.80 & -0.04 & +0.84 \\
\hline MD & Mid East & 1.65 & 0.81 & +0.84 \\
\hline VG & Southeast & 1.80 & 1.03 & +0.77 \\
\hline IA & Plains & 1.78 & 1.03 & +0.75 \\
\hline $\mathrm{CT}$ & New England & 3.00 & 2.25 & +0.75 \\
\hline VT & New England & 2.14 & 1.41 & +0.74 \\
\hline $\mathrm{AL}$ & Southeast & 1.55 & 0.86 & +0.68 \\
\hline AR & Southeast & 1.63 & 0.97 & +0.66 \\
\hline $\mathrm{TN}$ & Southeast & 1.71 & 1.10 & +0.61 \\
\hline $\mathrm{ME}$ & New England & 1.07 & 0.59 & +0.48 \\
\hline MO & Plains & 1.56 & 1.10 & +0.47 \\
\hline KY & Southeast & 1.42 & 0.94 & +0.47 \\
\hline NJ & Mid East & 2.44 & 2.30 & +0.14 \\
\hline PA & Mid East & 1.51 & 1.46 & +0.04 \\
\hline FL & Southeast & 1.05 & 1.15 & -0.10 \\
\hline WY & Rocky Mountains & 0.21 & 0.35 & -0.14 \\
\hline $\mathrm{SC}$ & Southeast & 1.56 & 1.75 & -0.19 \\
\hline MS & Southeast & 0.69 & 1.06 & -0.37 \\
\hline WV & Southeast & 0.30 & 0.74 & -0.44 \\
\hline NV & Far west & 0.48 & 0.97 & -0.49 \\
\hline $\mathrm{DC}$ & Mid East & 0.59 & 1.35 & -0.76 \\
\hline $\mathrm{HI}$ & Far west & -0.52 & 0.88 & -1.40 \\
\hline LA & Southeast & -1.47 & -0.03 & -1.44 \\
\hline $\mathrm{DE}$ & Mid East & -0.27 & 1.76 & -2.03 \\
\hline AK & Far west & -3.83 & -1.47 & -2.36 \\
\hline
\end{tabular}

Notes: Labor productivity growth is computed as the growth rate of the ratio between the levels of real GSP and total employment of the business sector in each state. 


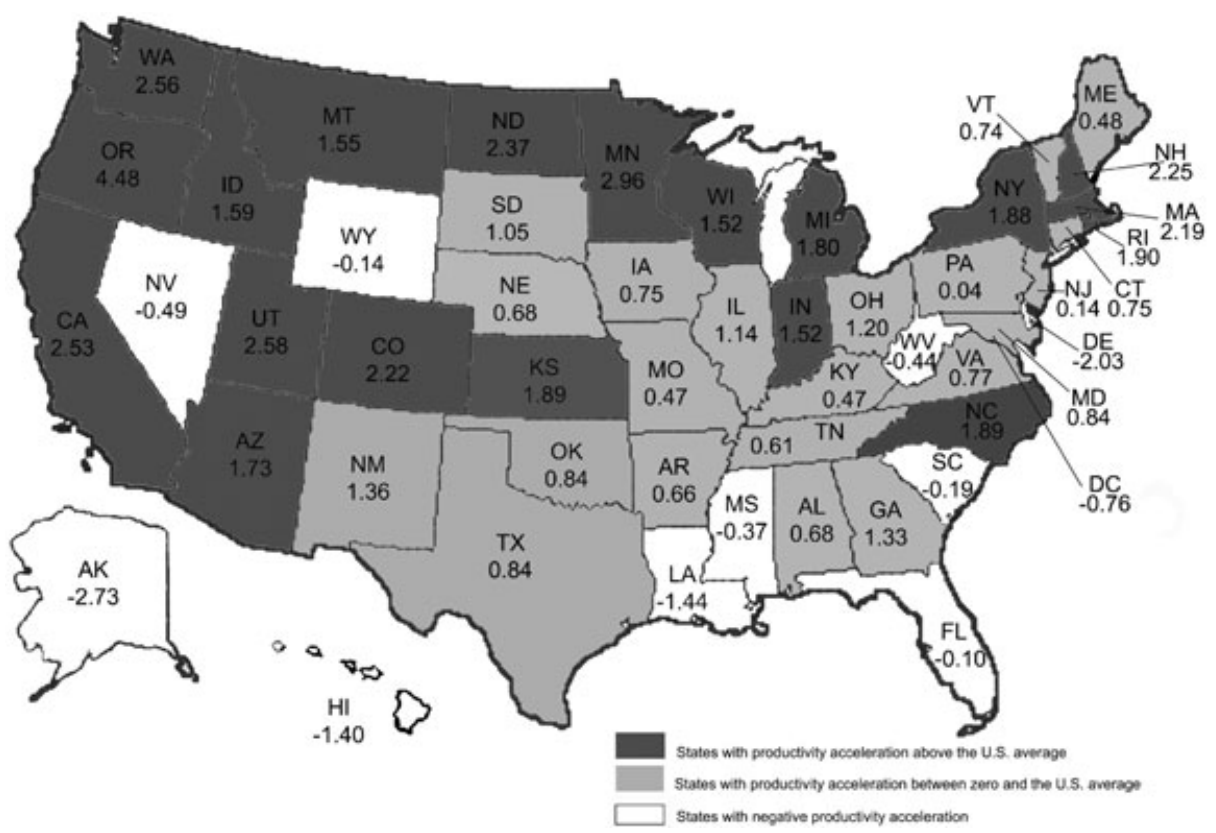

Figure 3. Acceleration in Labor Productivity Growth, 1995-2000 vs. 1986-95

year, and 24 states grew productivity beyond 2 percent per year, in 1995-2000. As a result, fast productivity growth was no longer exclusive to the few New England states, but extended to most regions in the country, in particular to the Western states.

Figure 3 provides a visual representation of the productivity growth acceleration in the U.S. in 1995-2000 with respect to 1986-95. Nineteen states, dark-grey colored in the picture, enjoyed accelerating growth in excess of 1.4 percentage points, i.e. above the average acceleration for the U.S. economy. Twenty-one states - in light grey in the picture - exhibit a "mildly positive" (between zero and 1.4 percent percentage points) variation in productivity growth, with the remaining 11 showing a deceleration in productivity growth. Although more broad-based than in the past, the productivity revival has mostly benefited the states in the West and the North East of the country.

To name some of the most significant turnaround episodes, productivity growth in the states of Washington, California and Colorado boomed to about 3.5 percentage points per year-more than 2.5 percentage points higher than in the previous period. Similar accelerating growth of about 2.5 percentage points per year or so was experienced in Idaho, Massachusetts, Minnesota, New Hampshire and North Dakota.

The majority of the fast accelerating states are IT-producing states. Six of the ten states with the biggest growth hikes in 1995-2000 were IT producers in 1997; the pair-wise correlation between IT production and productivity growth increases is 0.41 . This is prima facie unconditional evidence that the values of $\mathrm{SI}_{\text {ITprod }}$ may be good predictors for the growth jumps in 1995-2000. The pair- 
wise correlation with productivity jumps in the second half of the 1990s is positive for IT-using states as well. The correlation is strongest with STIROH $(\rho=0.52)$, but is also there, though smaller, with PCW and PCH $(0.34$ and 0.21 respectively). However, the correlation with productivity growth is nil with DEPT as the diffusion measure. Whether there is a significant partial correlation between IT intensity and productivity growth at the state level is explored in the following sections.

\section{IT and Labor Productivity Growth Across the U.S.}

In this section we test whether the states specialized in IT production or those that use IT most intensively have also enjoyed faster productivity acceleration. In other words, we are testing whether the IT revolution has had a geographical counterpart.

\section{Empirical Strategy}

Following Stiroh (2002b) and, more generally, the microeconometric approach to policy evaluation, we employ difference-in-difference estimation to learn about the effect of the IT revolution (the "treatment") on state productivity growth. To see what "treatment" means in this framework, take the production of IT manufacturing goods. When discrete indicators of IT intensity are used, the treatment is a binary variable, which takes the value of one when a state is specialized in IT production $\left(\mathrm{SI}_{\text {ITproduction }} \geq 1\right.$ ) and zero otherwise. If the continuous indicator of productive specialization is used, the treatment is a continuous variable, potentially ranging between zero, when a state is fully de-specialized in the production of IT manufacturing goods, and infinity, when a state is highly specialized in IT production.

Previous work on the effects of information technology on productivity growth (Gordon, 2000; Jorgenson and Stiroh, 2000; Oliner and Sichel, 2000) has taken 1995 as a breakpoint for U.S. productivity growth. Although formal testing procedures searching for unknown breakpoints have not provided fully conclusive results yet, the case for the presence of a break in the mid 1990s appears somehow strengthened as more recent data have become available. ${ }^{12}$ We therefore take 1995 as a breakpoint as well.

\footnotetext{
${ }^{12}$ The question whether 1995 is really the watershed commonly assumed in the new economy literature has been much investigated. The methodology of search for unknown breakpoints proposed by Hansen (2001) and implemented with monthly data through April 2001 indicates significant evidence of a shift in the mid 1990s, with some productivity series indicating a break in 1994 and some others in 1997. Stiroh (2002b) also employs the Hansen methodology and finds 1995 as a candidate breakpoint for U.S. productivity data through 2000, but this break is not statistically significant. The only significant breakpoint (for manufacturing) throughout this period is September 1993. The evidence in favor of the presence of a breakpoint in 1995 is strengthened, however, when the analysis includes more recent data (see Maury and Pluyard (2004) and Erber and Fritsche (2005), with data, respectively, through 2002Q4 and 2003Q4). However, for the pitfalls of employing the Hansen procedure to detect breaks very close to the end of the sample, it is instructive to read the caveats expressed by van Norden (2005). Interestingly, Kahn and Rich (2004) employ a regime-switching dynamic common factor model and find that, while the presence of a switch from a low-growth to a high-growth regime cannot be detected with productivity data only, the switch is there instead when supplemental information about the co-movements of productivity, consumption and labor compensation is used.
} 
The growth rate of labor productivity before and after 1995 is then contrasted for "treated" and "control" states. The underlying idea is that, around that time, the productivity effects of the Internet revolution began to show up most strongly in the states with an industry structure skewed towards highly IT-intensive production. To single out the influence of IT intensity of state groups on the post-1995 productivity acceleration, we test for the presence of deterministic trend breaks in the series of productivity growth for the state groups characterized by relatively high IT production and IT usage. But we also check whether the group of states specialized in non-IT durable good production has experienced accelerating productivity in parallel. This is a potentially useful check because durable goods producing industries have been traditionally (well before the start of the IT revolution) identified as the natural vehicles of technical change.

Our baseline specification with discrete specialization indicators is as follows:

$$
\begin{aligned}
& G_{s, t}=\alpha+\beta D+\sum_{1}^{3}\left(\gamma_{g} C_{g}+\delta_{g} D \cdot C_{g}\right)+e_{s, t} \\
& D=1 \quad \text { if } t>1995, \quad D=0 \quad \text { otherwise } \\
& C_{g}=1 \quad \text { if } \quad S I_{i}^{g} \geq 1, \quad C_{g}=0 \quad \text { otherwise }
\end{aligned}
$$

where $G_{s, t}$ is the growth rate of GSP per employed person in state $s$ at time $t$. A state $s$ belongs to the treated group $g$ (with $g$ representing the groups above) when the value of its SI index is equal to or bigger than one for the appropriate industry group, irrespective of the values taken by the SI index of that state for other industries. ${ }^{13}$ The parameter $\alpha$ is the mean growth rate for states not included in the state group $g$ in the pre-1995 period, $\gamma_{g}$ is the differential growth rate of group $g$ relative to the control group prior to $1995, \beta$ is the post-1995 acceleration for states not included in the treated group $g$ and $\delta_{g}$ is the differential productivity acceleration of group $g$ relative to all other states. In this way, we have split both the constant and the post-1995 dummy into group constants and group post-1995 dummies. Hence, equation (2) does not allow for fixed-effects for individual states, but it does allow for state-group fixed effects and group-specific slopes. In other words, we allow for state growth and growth accelerations to differ across state groups. The interpretation of the regression results is slightly different when the IT intensity indicator is continuous. Then $C=S I_{i}^{s}$ and the estimated $\delta$ is still an acceleration coefficient, but does not measure the change in the growth rate resulting from changing the state, but simply the change in productivity growth from changing the state specialization by a certain amount. ${ }^{14}$

In any case, with $\delta$ as our parameter of interest, our estimates are indeed of the difference-in-difference type. If the IT revolution has entailed a significant geographical dimension, it must be the case that the group of states classified as IT

\footnotetext{
${ }^{13}$ As a result, the same state may in principle belong to two groups with high specialization.

${ }^{14}$ In the policy evaluation jargon, the discrete indicator case amounts to asking by how much the average wage goes up by taking part in a training program, while, in the continuous indicator case, the question asked is how much the average wage goes up by taking part in a six-month as opposed to a three-month training program.
} 
intensive (producers or users) has enjoyed accelerating productivity over and above the acceleration experienced by the "control" states. Even though we also report OLS results, our preferred equation is estimated by weighted least squares (WLS), with the square roots of current output levels as weights and standard errors corrected for heteroskedasticity and within-state autocorrelation. ${ }^{15}$

\section{Baseline Results}

Table 4 reports our baseline results, i.e. the estimated post-1995 acceleration coefficients (the $\delta$ in equation (2)) for the various groups of states. Columns $1-4$ report WLS and OLS estimates with discrete indicators of IT intensity for the full sample and the restricted sample of states for which $\mathrm{SI}_{\mathrm{ITprod}}$ was proxied with data for a bigger aggregate (see Section 2). ${ }^{16}$ The full sample includes 714 observations for 51 states over 14 years (1986-2000). The restricted sample includes 630 observations originating from 45 states over the same period. Columns 5-8 show WLS and OLS estimates with continuous indicators of IT intensity.

For each specification in Table 4, statistical significance does not differ much across methods of estimation. WLS estimates always produce lower values of the residual variation (RMSE) than OLS estimates, and we tend to regard WLS results as our preferred results. First, the coefficient of IT production is well determined and positively and sizably affects productivity growth. When the discrete indicators are employed, the coefficient of $\mathrm{SI}_{\mathrm{ITprod}}$ is always statistically significant at the 1 percent level. The point-wise estimates of the IT production coefficient imply that IT-producing states enjoyed accelerating productivity growth for about 1.2-1.4 percentage points beyond that of the control group in 1995-2000. This result holds within both the full sample and the restricted sample. The results from the continuous indicators of IT production are less precisely measured. They are statistically significant at the 5 or 10 percent level and imply a less pronounced effect: if $\mathrm{SI}_{\text {ITprod }}$ increases by one standard error, this leads to a productivity acceleration of about $0.5-0.6$ percentage points beyond that of the control group.

Second, the estimated coefficient for IT using states is also usually positively related to productivity but is less significant across specifications than the coefficient for the IT-producing states. With the discrete IT intensity indicators, the estimated acceleration coefficient for IT using states is not statistically significant in the full sample, but it is significant in the restricted sample. When using continuous indicators, the estimated coefficient is significant at the 1-5 percent level with the full sample and at the 5-10 percent with the restricted sample. The point-wise estimates from discrete indicators (in columns 3 and 4) indicate an acceleration of about $0.5-0.7$ percentage points with respect to the control group

\footnotetext{
${ }^{15}$ To make sure that our results are not driven by the specific weights chosen here, we also checked whether our results are sensitive to the use of different weights, such as the initial level of output in 1987 or the square root of current employment levels. Results are unaffected, whichever weight is employed.

${ }^{16}$ There are other good reasons to leave Alaska, Hawaii and DC out of the sample (and Barro and Sala-i-Martin (1990) indeed did so). Hawaii is quite far away from the other 50 states, while GSP data for Alaska and DC are instead potentially biased by interstate commuting, as emphasized in the Data Appendix. These circumstances may well influence the recorded values of labor productivity and IT usage indicators. And indeed Alaska and Hawaii are among the countries showing the biggest deceleration in productivity growth throughout the 1990s (see Table 3), while being among the most heavily intensive users of PCs (see Table 1).
} 


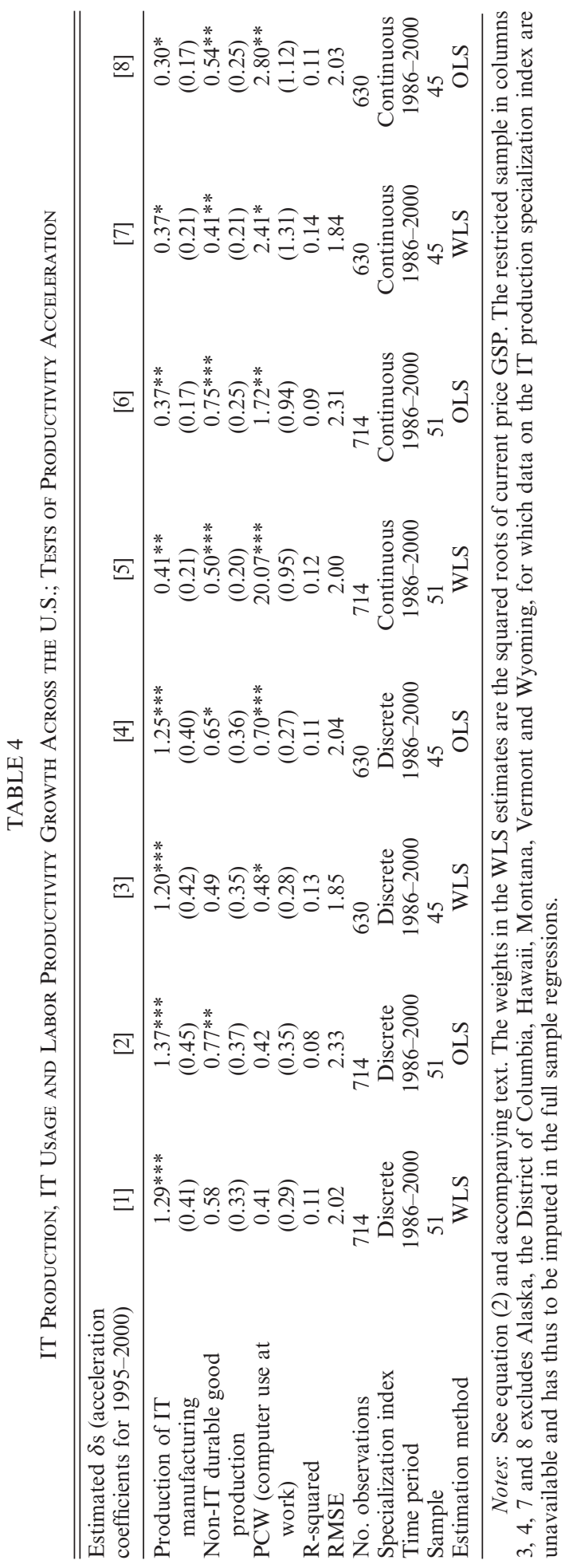

(C) 2006 The Authors 
in 1995-2000. This is roughly half as much as the estimated acceleration of IT-producing states when the discrete indicator is employed. When continuous indicators are used, the estimated acceleration from a one-standard-deviation increase in $\mathrm{SI}_{\text {ITuse-pcw }}$ is of the same order of magnitude as that for the IT production coefficient (0.5-0.7 percentage points).

Third, the acceleration coefficients of non-IT durable goods productionwhich are always included as a control in all regressions - do not present a systematic pattern of statistical significance across specifications. However, their point-wise estimates are sometimes significant and, when statistically different from zero, not too far from half a percentage point as well.

The different results obtained with discrete and continuous indicators are puzzling and deserve some further comment. The lower estimates of the coefficients for IT production when the continuous indicator is employed signal that the huge differences in the values of the SI indices for IT manufacturing production between, say, New Mexico and New Hampshire, on the one hand, and DC and Alaska, on the other, are only very mildly reflected in differences in growth rates acceleration in the second half of the 1990s. Hence being an IT-producing state or not is what makes a difference, not how much a state is specialized in IT production.

The opposite applies for IT usage. As emphasized above, the dividing line between the states specialized in IT usage and those which are not is not clear-cut. The statistically insignificant coefficients in columns 1-2 and the significant coefficients in columns 5-8 indicate that, for IT use, the $0-1$ categorization is too coarse a description of the relation between IT usage and productivity growth. In conclusion, the results in Table 4 should not be taken to imply that the relation between IT usage and productivity growth is unstable, but rather that this relation is linear and smooth. Moreover, the statistical significance of the continuous indicators based on PCW also indicates that the possible multi-collinearity between the SI for IT production and PCW is not too high.

\section{Extensions to Baseline Results}

The thrust of our baseline results continues to hold in other circumstances and specifications. We look at the details in turn.

\section{Alternative Indicators of IT Usage}

In Section 2, we motivated our preference for PCW as our preferred indicator of IT usage. However, we are aware that PCW, being measured in 1997, may partly be the result of, rather than the cause of, the productivity revival. In this sub-section, we present evidence from WLS regressions on the extent to which our baseline results change when alternative indicators of IT usage-namely $\mathrm{PCH}$, STIROH and DEPT - are employed. PCH is the indicator constructed from 1994 data on the household ownership of PCs, while STIROH and DEPT are state indicators of IT usage obtained from nationwide data on IT investment and capital at industry level. As discussed above, to compute STIROH, the line between IT users and non-users is drawn at the median of the industry distribution; to compute DEPT, the line is drawn roughly at the top quartile of industries ranked by IT usage. The results from these experiments are reported in Table 5. 


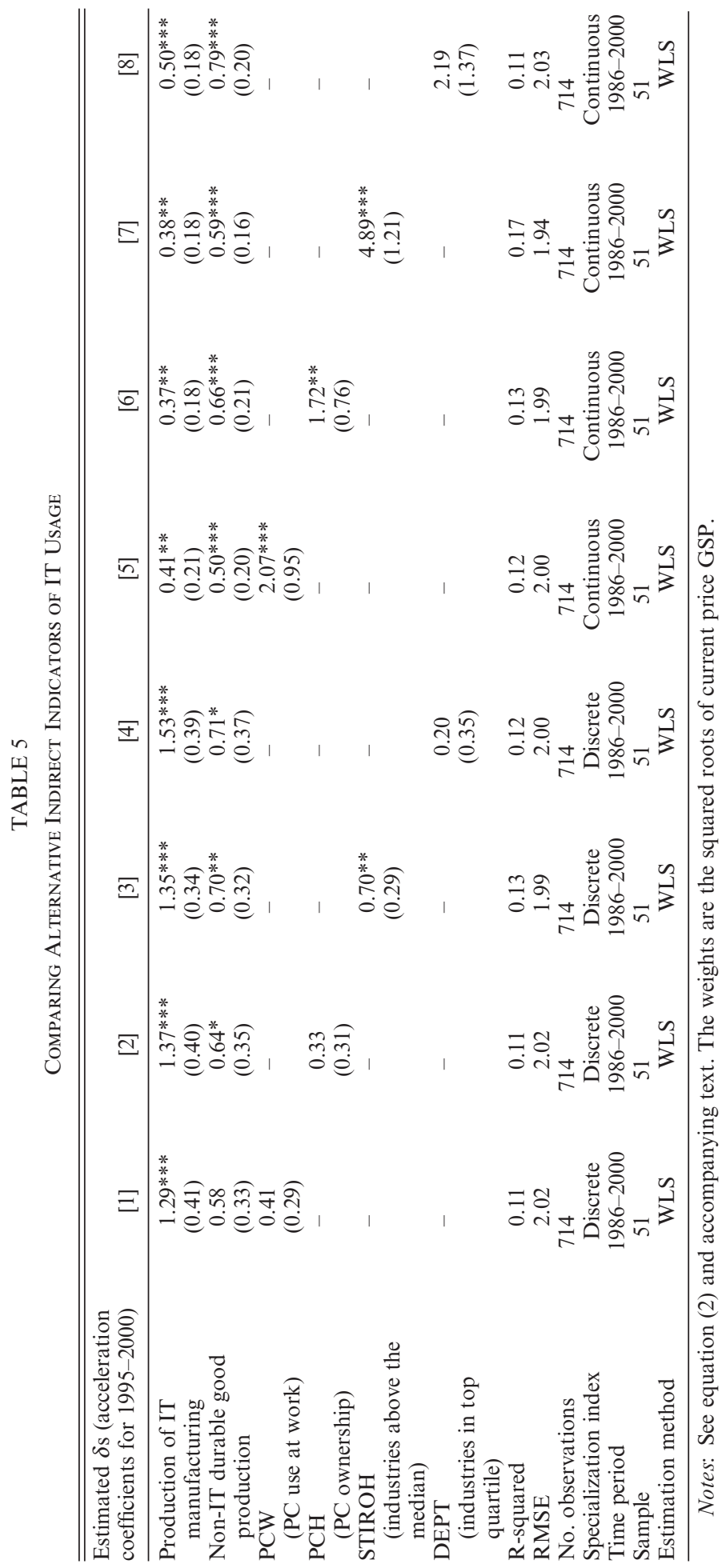

(C) 2006 The Authors 
For the sake of comparison we again report in columns 1 and 5 the results from Table 4 obtained from measuring IT usage by (discrete and continuous) PCW. ${ }^{17}$ The results in Table 5 show that DEPT is never statistically significant, while STIROH is strongly significant. This suggests that the criterion by which a state (or eventually an industry) is deemed "IT using" is important. The resulting sensitivity to alternative definitions of IT industries also indicates that relying on a direct state indicator of IT usage is probably preferable. The variable $\mathrm{PCH}$, instead, behaves very similarly to PCW. It is not significant with the discrete indicators, while it is with the continuous indicators. This strengthens the robustness of our baseline results: by using a 1997 measure of IT diffusion, we are measuring something closely related to a variable measured in 1994. At the same time, another important result from Table 4 still holds: the continuous indicators of IT use are more often significant (or close to significant) than discrete indicators, even with other indicators of IT usage.

\section{Varying the Time Interval}

As explained in Section 2, our analysis spans from 1986 to 2000 only because of our preference to use chained data for real GSP so as not to incur the upper-level substitution bias. However, by constraining ourselves to the period 1986-2000, we may be focusing on a too short period. More specifically it might be that, by 1986 , some states were already on their way out of the 1970s productivity slowdown. Extrapolating our analysis backwards would allow us to evaluate whether the detected trend breaks from 1995 onwards hold when the 1970s and the early 1980s, i.e. the productivity slowdown decades, are included as well.

Luckily, the data for the U.S. published by the BEA go back to 1977, thereby including the bulk of the productivity slowdown period. Despite the fact that these series refer to real GSP computed from fixed-weight indices - a practice abandoned by the BEA in recent years - we are able to test whether our conclusions, in particular the more contentious ones regarding the importance of IT usage, carry over to this extended sample.

In Table 6, we present additional evidence varying the sample size along the time dimension for our difference-in-difference estimation. On the whole the findings are very similar to those in Table 5. Some of the estimated coefficients are only slightly enhanced in terms of statistical significance and size. This applies in particular to the variable measuring the state intensity of IT production of manufacturing goods. This is highly significant (at the 1 percent level), with point-wise estimates in excess of 1.5 when the discrete indicators are used. Significance and size of the variable measuring the specialization in non-IT durable goods production is also strengthened when compared to the results from Tables 4 and 5. Even for IT usage the pattern of partial correlation is largely the same as in previous tables: continuous indicators perform better than discrete indicators, PCW and PCH correlate with productivity and STIROH is positively and significantly correlated with the productivity acceleration. The only difference from the estimates

\footnotetext{
${ }^{17} \mathrm{We}$ omit reporting OLS results and we also do not report the results for the restricted sample. The pattern of coefficient significance in these cases is the same as in Table 4: OLS does not make a difference, while the statistical significance of IT usage is enhanced in the restricted sample.
} 


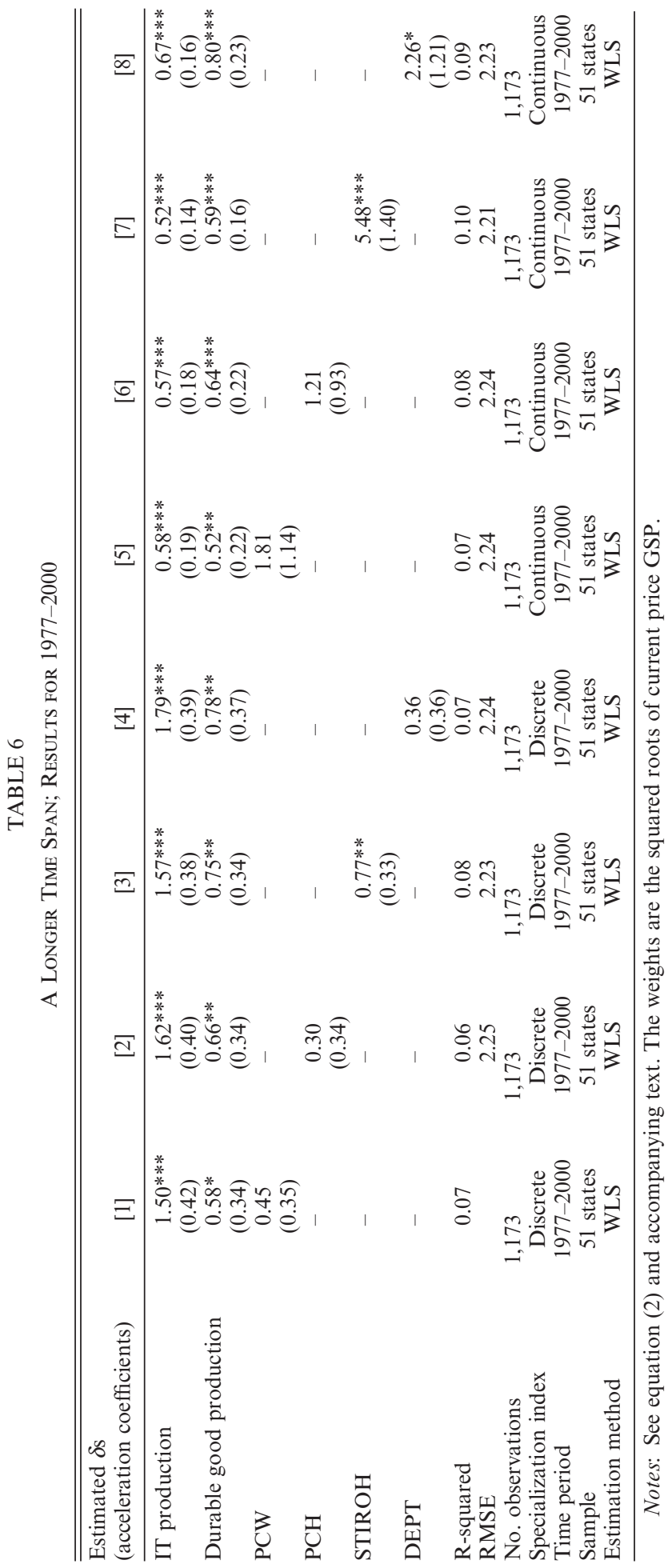

(C) 2006 The Authors 
over the shorter time horizon is that DEPT, while as usual insignificant with the discrete indicators, is instead mildly significant (at the 10 percent level) with the continuous indicators. The results from the restricted sample of 45 states (not reported here) are also similar to the results for the full sample. In conclusion, our statistical results improve somewhat when a longer time period is considered. Yet our baseline estimates remain our preferred results as they are obtained from chained GSP data.

\section{Relating State and Industry Evidence}

The most solid empirical finding in the previous section is the statistically significant acceleration in labor productivity growth experienced by IT-producing states beyond the control group of other states. Part of this post-1995 productivity acceleration is also present in IT-using states. However, this result is slightly less robust than the one obtained for the IT-producing states. At first sight, these pieces of evidence may look at variance with common knowledge. A variety of studies, employing aggregate, industry and company data, have stressed the crucial importance of IT usage - and its related organizational changes - for the U.S. productivity revival. ${ }^{18}$ This raises the question of how our state-based evidence can be reconciled with the evidence from such other data sources. A closer inspection of state-industry productivity data shows that our results are not inconsistent with these earlier observations.

Starting from the fully-fledged state-industry disaggregation of GSP and employment, we aggregate industries across industry groups within each state, therefore computing GSP, employment and labor productivity for the three industry sub-aggregates of "IT-producing," "IT-using" and "other industries" for each state. Such sub-aggregates at the state level are necessarily computed from the SIC two-digit definitions of industry groups. Hence "IT-producing industries" is the sum of "industrial machinery" and "electronic and electrical products," and the "IT-using industries" sub-aggregate is Stiroh's list of IT-using industries, minus "industrial machinery" and "electronic and electrical products." The "other industries" sub-aggregate is made of all the remaining non-farm private industries in each state. One complication was that the BEA must sometimes suppress state-industry information, in particular for small states, in order to avoid disclosure of confidential information. To be able to fill these gaps and compute the industry sub-aggregates of interest, we have thus to impute data for such industries for a few years and states. ${ }^{19}$ This allows us to compute GSP, employment and labor productivity for the three industry sub-aggregates of IT-producing, IT-using and other industries for each state.

\footnotetext{
${ }^{18}$ The most often quoted ones are: Oliner and Sichel, 2000; Jorgenson and Stiroh, 2000; Stiroh, 2002b; Nordhaus, 2002; Triplett and Bosworth, 2003; and Brynjolfsson and Hitt, 2003.

${ }^{19}$ The imputation of the missing cells is carried out so as to satisfy the adding up for the total industries in that state in that particular year, while keeping the state-industry shares of the relevant (GSP or employment) missing cells constant with respect to contiguous years. We usually employ the GSP or employment share at $t+1$ to fill a gap at $t$. If the share at $t+1$ is missing, then we use the share at $t-1$. If $t-1$ is missing as well, then we use the share at $t+2$ and so on.
} 
We then further aggregated our industry estimates across groups of states, computing the corresponding three sub-aggregates of "IT-producing states," "ITusing states" and "other states." "IT producing states" includes those states with values of $\mathrm{SI}_{\text {ITprod }}$ bigger than or equal to one in Table 1. "IT-using states" includes those states with values of $\mathrm{SI}_{\mathrm{STIROH}}$ bigger than or equal to one and not included in the list of the IT-producing states. "Other states" includes all the remaining states. Eventually we compute the productivity acceleration in 1995-2000 with respect to 1986-95 and the 1995 value added shares of IT-producing, using and other industries in IT-producing, using and other states. By multiplying the industry and state shares, we can then measure the "within" contribution of each industry group to productivity acceleration in each state group. ${ }^{20}$

The results are shown in Figure 4: the bars, scaled on the left part of the graph, represent productivity growth rates, while the lines, scaled on the right part of the graph, represent value added shares. Panel (a) in Figure 4 shows that the exceptional productivity acceleration of IT-producing states in 1995-2000 (+2.6 percentage points per year; about 1.5 percentage points higher than the acceleration in the other states) is the result of two components. First, it depends on the high growth contribution from IT-producing industries. This is due to both rapid acceleration (+6.8 percentage points per year) and a comparatively high value added share of these industries (about 5 percent of non-farm private industries) in the IT-producing states. Second, the rapid productivity acceleration of IT-producing states is also accounted for by the high growth contribution of IT-using industries whose somewhat lower-but still substantial-acceleration $(+2.8$ percent) applies to more than half of the GSP of the IT-producing states. Finally, the contribution from "other industries" to the productivity acceleration in the IT producing states has been nil.

A second piece of evidence concerns the industry group contributions to the productivity acceleration in IT-using states (panel (b)). The relatively low 19952000 productivity acceleration in this group of states ( +1.4 percentage points) is entirely accounted for by IT-using industries. The growth contribution from IT-using industries is in fact about the same as in IT-producing states (as a result of slightly lower growth but also definitely bigger value added shares). Instead the slower acceleration in this group of states mostly originates from the other industry groups. The "IT-producing industries" sub-aggregate gives a much lower contribution in IT-using states than in IT-producing states. Moreover, although less importantly, the "other industries" sub-aggregate (about one half of GSP in IT-using states) gives a negative contribution in the IT-using states.

In conclusion, as in previous studies, we find confirmation that both IT-producing and IT-using industries enjoyed above-average acceleration. Yet the contribution to productivity acceleration from IT-producing industries was mostly concentrated in IT-producing states, which explains the strong statistical significance of IT production in our state acceleration regressions. The contribution of IT-using industries to productivity acceleration was instead more uniformly

\footnotetext{
${ }^{20}$ The product of the growth acceleration times the initial value added share is the so called "within" contribution to productivity acceleration.
} 
(a) IT-Producing States

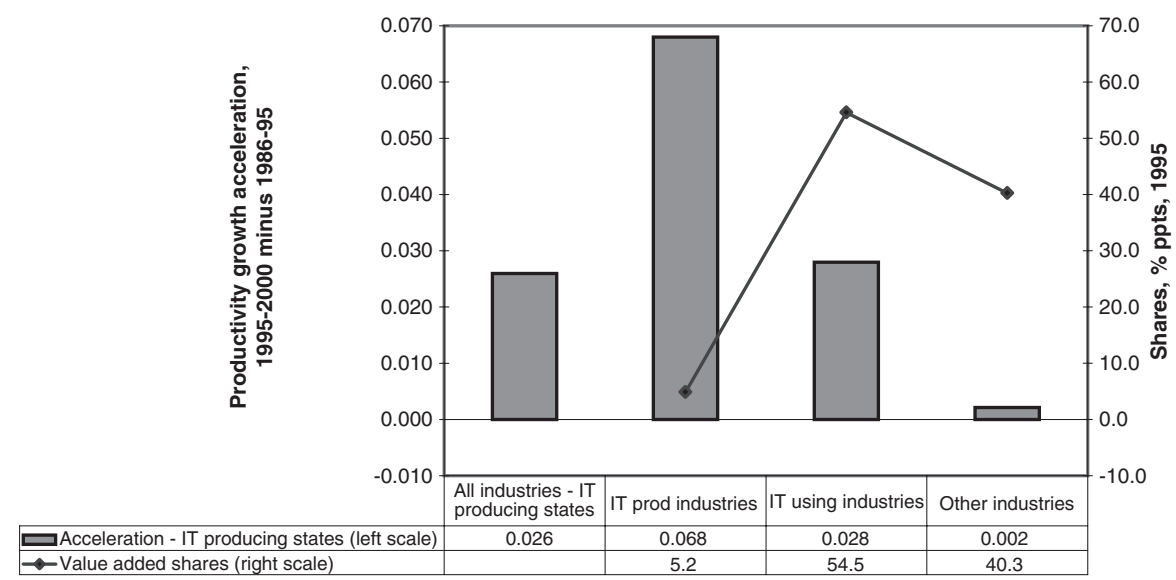

(b) IT-Using States

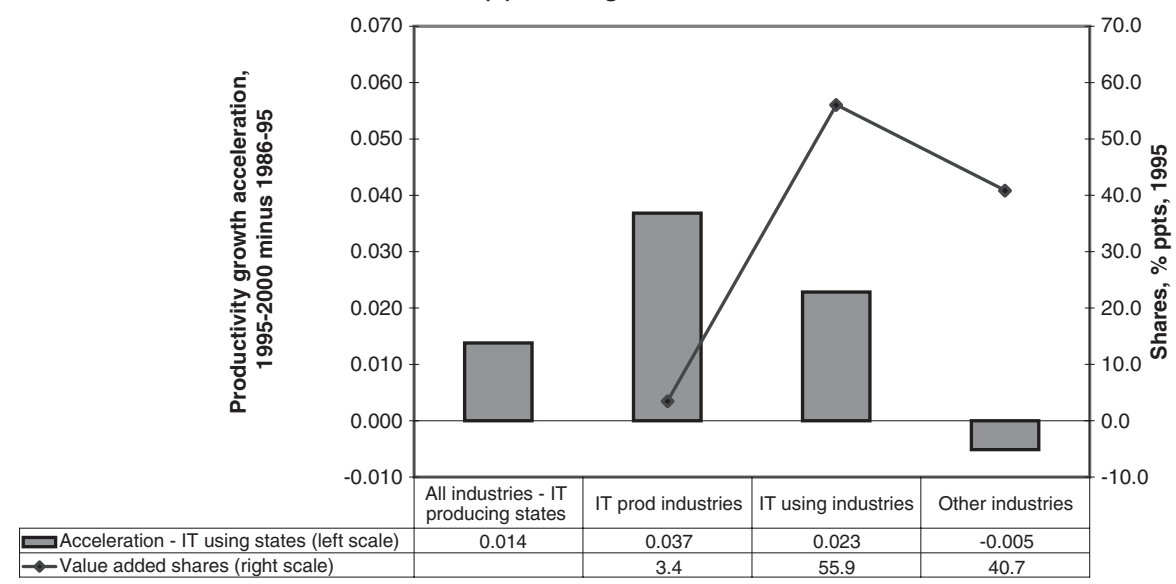

(c) Other States

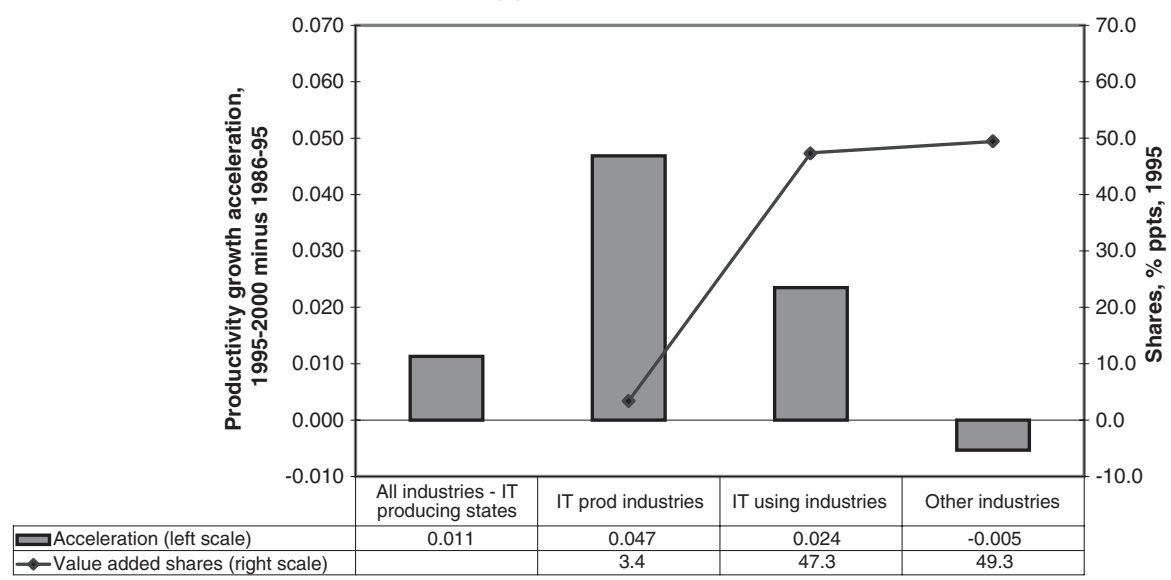

Figure 4. Productivity Growth Acceleration and Industry Composition 
spread across the U.S., which partly explains the lower coefficient for IT usage in our state acceleration regressions. Finally, the zero or negative contribution to productivity acceleration from other industries is consistent with the results in Stiroh (2002b) and Nordhaus (2002).

We interpret our results in this section as bridging the gap between the state evidence presented in this paper and the common wisdom on the relation between IT intensity and productivity growth for the aggregate U.S. economy. The positive and statistically significant productivity jump experienced by IT-producing states is not the result of the exceptional performance of IT-producing industries only, but the counterpart of the contribution from IT-using industries to productivity acceleration. The less robust statistical significance of IT-using states is not due to the missing effect of IT usage on productivity but rather to a lower growth contribution of IT-producing and other industries in these states.

\section{Conclusions}

This paper contributes to the debate on the extent to which IT production and usage have contributed to the productivity revival in the U.S. economy. It exploits the geographical dimension of the IT revolution in the U.S. economy by analyzing cross-state time series correlation of labor productivity growth and IT intensity. Our findings are in accordance with the prevailing views on the crucial importance of IT production and use in the U.S. productivity revival.

In short, we find three main results. First, states with above-average production intensity of IT manufacturing show bigger productivity accelerations than other states. Second, states with above-average IT diffusion show higher productivity growth than other states. Yet, while the result for IT-producing states is robust, the result for IT-using states is less so across specifications. Third, and perhaps most important, these results are in line with previous findings that pointed to the crucial importance of IT usage for the U.S. productivity revival. We replicate previous evidence showing that both IT-producing and IT-using industries enjoyed above-average acceleration. But we also show that the positive and statistically significant productivity acceleration experienced by IT-producing states is not the mere counterpart of the exceptional performance of IT-producing industries, but also of the contribution from IT-using industries. In parallel, the less robust statistical significance of IT-using states is not due to the lack of an effect of IT usage on productivity but rather to a lower growth contribution of IT-producing and other industries in these states. This largely reconciles our state-level evidence with the evidence from previous studies.

Much remains to be done as the progress towards providing better data at the state level goes on. For example, to capture whether quality improvements equally affect the same industries across states, it would be important to compute GSP using state-specific price deflators. Other issues are not specific to the state-level framework of analysis. As suggested by Griliches (1992) and Triplett (1996), and more recently discussed by Triplett and Bosworth (2004) and Timmer and Inklaar (2005), output in the IT-using sectors (mostly services, such as wholesale trade, finance, insurance, and legal services) is still imperfectly measured. As long as state GSP becomes more and more tilted towards the production of services, the need to 
satisfactorily deal with these measurement issues will become crucial for improving our knowledge of the link between technology and productivity.

\section{DATa APPENDiX}

\section{Measuring Output at the State Level}

As emphasized in the main text, the Gross State Product for each state is the sum of the GSP for all industries in the state. An industry's GSP is its value added, thus the difference between its gross output and the value of intermediate inputs. The GSP estimates are prepared for 81 NAICS-based industries for 1998-2003 and for 63 SIC-based industries for 1977-2001. We mainly used the SIC classification, the only amenable for time series analysis over a long period of time. For each industry, GSP equals the sum of three components, the employees' compensation, indirect business tax and non-tax liabilities, and property type incomes. To estimate the employees' compensation item, the BEA relies upon two components of the State Personal Income series, namely "wage and salary accruals" and "other labor incomes." "Wage and salary accruals" is then used to allocate employers' contributions for social insurance-the other component of employees' compensation not measured in the personal income series - to states. The property-type income component of GSP is made of proprietors' income and "other capital charges." A variety of data sources and levels of aggregation, depending on the industry type, are used to derive this item. Among the various adjustments, data for headquarters of multi-establishment firms are reassigned from the states where establishments are located to the states where headquarters are located. For private services-producing industries, the estimates of other capital charges are based on data of revenues and payrolls from economic censuses, on data on income and expenses from financial reports that firms file with Federal agencies or on unpublished BEA estimates of wage and salary accruals by State.

For a proper measure of labor productivity, all of the above mentioned components would be required to be recorded by place of work or attributed to the place where the establishments are located in practice. In fact, wage and salary accruals, other labor income, and indirect business tax and non-tax liabilities are mainly derived from source data that are reported and recorded by place of work. The estimates of proprietors' income, conversely, are derived from source data that are reported by the tax-filing address of the recipient-usually corresponding to the proprietors' residence. Due to the variety of data sources and estimating procedures, it is hard to say if "other capital charges" is really attributed to states where production occurs. Nevertheless, as long as data are reassigned to states where the administrative offices of multi-establishment companies are located, even the "other capital charges" item may be exposed to a bias.

The BEA does indeed present a distinction between place of residence and place of work for some components of personal income. An adjustment coefficient to allocate the labor earnings of interstate commuters and the wages and salaries of border workers is made available by the BEA at the state level, but not at the 
industry level. As more extensively discussed in Bernat and Repice (2000), the impact of this adjustment is practically immaterial for the bulk of the U.S., except for small states (Connecticut, Delaware, Rhode Island, New Jersey and DC) and states with substantial portions of their economies concentrated in large metropolitan areas that extend across state boundaries (Virginia and, again, DC). In these states, interstate commuting is high and this is reflected in negative values of the adjustment ratio. Alaska also shows a high adjustment ratio due to its relatively high number of migrants.

The second problem concerns the distribution of corporate profits and other aggregates of property-type income among states. In fact, except for banking and some other regulated industries, state-level data on corporate profits and other property-type items are generally not available. With regard to the distribution of corporate profits across states, although the magnitude of the deviation from true location is not known, it is subject to various counterbalancing forces that might actually reduce its significance for a large number of states. This issue may be particularly relevant for states with above-average localization of administrative offices of multi-state companies (notably New York).

To gain some insights, we attributed the amount of national profits to the states proportionally to their labor share and checked whether the ratio of the attributed profits to state property-type income deviates substantially from the value obtained for the whole economy. There was no significant deviation, except for Alaska (which shows a share below the national average by 0.11 percentage points) and Wyoming (0.07 points below the average). Yet, importantly, none of the ex-ante most likely candidates (New York, California) show substantial deviations from zero.

Finally, we also attempted to control for possible biases by comparing index values based on GSP to alternative values based on data based on employment by place of work. The fraction of employment exposed to distorting effects is about 16 percent, whereas for GSP it amounts to about 40 percent. The computation of a measure of specialization based on employment rather than on GSP data, does usually lead to very similar results. Only in a few cases (Oregon, New Mexico and Vermont), employment data fail to register a significant presence of IT producing and using industries, while GSP does. For example, in Vermont, releasing employment data would imply disclosing the operations of individual establishments or companies. Extrapolations from previous data, however, confirm the relevance of IT-producing industries for Vermont too.

\section{Lists of IT-Producing and IT-Using States}

\subsection{IT-Producing States}

Criterion: 1997 NAICS classification code 334: "Computer and Electronic Product Manufacturing"

- New Mexico

- New Hampshire

- Oregon

- Arizona

- South Dakota 
- Idaho

- Massachusetts

- California

- Vermont

- Colorado

- Texas

- Minnesota

- Oklahoma

\subsection{IT-Using States}

Criterion: PCW (employment share of households with PC use at work, 1997)

- Maryland

- New Hampshire

- Washington

- Colorado

- Arizona

- New Jersey

- New Mexico

- Alaska

- Vermont

- Virginia

- Massachusetts

- Missouri

- Wisconsin

- California

- Indiana

- Michigan

- Texas

- Utah

- Ohio

- Oregon

- Maine

- Pennsylvania

\subsection{IT-Using States}

Criterion: STIROH (above-average output share of top 50 percent IT-using industries)

- New York

- Massachusetts

- South Dakota

- Connecticut

- Rhode Island

- District of Columbia

- Delaware

- Colorado

- Arizona 
- Florida

- Vermont

- New Hampshire

- Kansas

- Minnesota

- Illinois

- Missouri

- California

- Washington

- Iowa

- Nebraska

- Pennsylvania

- Wisconsin

- Oregon

- Georgia

- Utah

\section{REFERENCES}

Barro, Robert J. and Xavier Sala-i-Martin, "Economic Growth and Convergence Across the United States," NBER Working Paper no. 3419, August 1990.

Beemiller, Richard M. and Clifford H. Woodruff III, "Gross State Product by Industry, 1977-98," Survey of Current Business, 69-90, October 2000.

Beemiller, Richard M. and George K. Downey, "GSP by Industry, 1992-1999," Survey of Current Business, 159-72, August 2001.

Bernat, G. Andrew, Jr. and Eric S. Repice, "Industrial Composition of State Earnings in 1958-98," Survey of Current Business, 70-8, February 2000.

Brynjolfsson, Erik and Lorin M. Hitt, "Computing Productivity: Firm-Level Evidence," Review of Economics and Statistics, 85, 793-808, 2003.

Daly, Mary and Fred Furlong, "Gains in US Productivity: Stopgap Measures or Lasting Change?" Federal Reserve Bank of San Francisco Economic Letter, 2005-05, March 11, 2005.

Daveri, Francesco, "Delayed IT Usage: Is It Really the Drag on European Productivity?" CESifo Economic Studies, 50, 397-421, 2004.

Erber, Georg and Ulrich Fritsche, "Estimating and Forecasting Aggregate Productivity Growth Trends in the US and Germany," DIW Berlin, Discussion Paper 471, 2005.

Friedenberg, Howard L. and Richard M. Beemiller, "Comprehensive Revision of GSP by Industry, 1977-1994," Survey of Current Business, 15-41, June 1997.

Gordon, Robert J., "Does the 'New Economy' Measure Up to the Great Inventions of the Past?" Journal of Economic Perspectives, 14, 49-74, 2000.

, "Hi-tech Innovation and Productivity Growth: Does Supply Create Its Own Demand?" NBER Working paper \#9437, January 2003.

, "Why Was Europe Left at the Station When America's Locomotive Departed?" NBER Working Paper 10661, August 2004.

Griliches, Zvi, "Introduction," in Zvi Griliches (ed.), Output Measurement in the Service Sectors, NBER Studies in Income and Wealth, Chicago University Press, 1992.

Hansen, Bruce E., "The New Econometrics of Structural Change: Dating Breaks in U.S. Labor Productivity," Journal of Economic Perspectives, 15, 117-28, 2001.

Inklaar, Robert, Mary O’Mahony, and M. Timmer, "ICT and Europe's Productivity Performance: Industry-Level Growth Accounting Comparisons with the United States," Groningen Growth and Development Center, Research Memorandum GD-68, December 2003.

Jorgenson, Dale W. and Kevin J. Stiroh, "Raising the Speed Limit: U.S. Economic Growth in the Information Age," Brookings Papers on Economic Activity, 125-235, 2000.

Jorgenson, Dale W., Mun S. Ho, and Kevin J. Stiroh, "Projecting Productivity Growth: Lessons from the U.S. Growth Resurgence," CESifo Economic Studies, 49, 27-47, 2003.

Kahn, James A. and Robert W. Rich, "Tracking the New Economy: Using Growth Theory to Detect Changes in Trend Productivity," Federal Reserve Bank of New York, mimeo, March 31, 2004. 
Maury, Tristan-Pierre and Bertrand Pluyaud, "The Breaks in Per Capita Productivity Trends in a Number of Industrial Countries," Notes d'études et de recherche de la Banque de France, 111, 2004.

McGuckin, Robert H., M. Spiegelman, and B. van Ark, "The Retail Revolution: Can Europe Match the US Productivity Performance?" Perspectives on a Global Economy, The Conference Board, New York, 2005.

MGI (McKinsey Global Institute), "US Productivity Growth 1995-2000. Understanding the Contribution of Information Technology Relative to Other Factors," Report, October 2001. ,"US Productivity After the Dotcom Bust," Report, December 2005.

Nordhaus, William D., "Productivity Growth and the New Economy," Brooking Papers on Economic Activity, 211-59, 2002.

Oliner, Stephen and Daniel E. Sichel, "The Resurgence of Growth in the Late 1990s: Is Information Technology the Story?" Journal of Economic Perspectives, 14, 3-22, 2000.

Stiroh, Kevin J., "Are ICT Spillovers Driving the New Economy," The Review of Income and Wealth, 48, 33-57, 2002a.

, "Information Technology and the US Productivity Revival," American Economic Review, 92, 1559-76, 2002b.

Timmer, Marcel and Robert Inklaar, "Productivity Differentials in the US and the EU Distributive Trade Sector: Statistical Myth or Reality," GGDC Research Memorandum, GD-76, Groningen, 2005.

Triplett, Jack, "High-Tech Industry Productivity and Hedonic Price Indices," OECD Proceedings: Industry Productivity, International Comparison and Measurement Issues, Paris, 1996.

Triplett, Jack and Barry Bosworth, "Baumol's Disease Has Been Cured: IT and Multifactor Productivity in US Services Industries," Federal Reserve Bank of New York, Economic Policy Review, September, 23-33, 2003.

, Productivity in the US Services Sector. New Sources of Economic Growth, Brookings Institution, Washington DC, 2004.

U.S. Department of Commerce, "A Nation Online: How the Americans Are Expanding their Use of the Internet," National Telecommunications and Information Administration and the Economics and Statistics Administration, Joint Report, February 2002.

van Ark, Bart, "Measuring the New Economy: An International Comparative Perspective," The Review of Income and Wealth, 48, 1-14, March 2002.

van Ark, Bart, Robert Inklaar, and Robert H. McGuckin, "Changing Gear Productivity, ICT and Service Industries: Europe and the United States," in J. F. Christensen and P. Maskell (eds), The Industrial Dynamics of the Digital Economy, Edward Elgar, 2003a.

-, "ICT and Productivity in Europe and the United States: Where Do the Differences Come From?" CESifo Economic Studies, 49, 295-318, 2003b.

van Norden, Simon, Are We There Yet? Looking for Evidence of a New Economy, HEC Montreal, October 2005. 